\title{
A comparison of semen diluents on the in vitro and in vivo fertility of liquid bull semen
}

\author{
Edel M. Murphy, ${ }^{\dagger} \dagger$ Craig Murphy, $\ddagger$ Ciara O’Meara, $\dagger$ Gemma Dunne, $\dagger$ Bernard Eivers, $\dagger$ Patrick Lonergan, $\S$ \\ and Sean Fair*1 \\ *Laboratory of Animal Reproduction, Department of Life Sciences, Faculty of Science and Engineering, University of Limerick, Castletroy, \\ Limerick, V94 T9PX, Ireland \\ †National Cattle Breeding Centre, Naas, Co. Kildare, W91 WF59, Ireland \\ $\ddagger$ Animal and Grassland Research and Innovation Centre, Teagasc, Moorepark, Fermoy, Co. Cork, P61 C996, Ireland \\ $\S$ School of Agriculture and Food Science, University College Dublin, Belfield, Dublin 4, D04 N2E5, Ireland
}

\section{ABSTRACT}

The aim of this study was to assess the effect of semen diluent on calving rate $(\mathrm{CR})$ following artificial insemination with liquid bull semen stored for up to $3 \mathrm{~d}$ postcollection. In experiment 1 , the effect of storing liquid semen maintained at a constant ambient temperature in 1 of 7 different diluents [Caprogen (homemade), OptiXcell, BioXcell, BullXcell, INRA96, NutriXcell, or AndroMed (all commercially available)] on total and progressive motility was assessed on d 0 , 1, 2, and 3 postcollection. In experiment 2, the field fertility of liquid semen diluted in Caprogen, BioXcell, or INRA96 and inseminated on d 1, 2, or 3 postcollection was assessed in comparison to frozen-thawed semen (total of $n=19,126$ inseminations). In experiment 3 , the effect of storage temperature fluctuations (4 and $18^{\circ} \mathrm{C}$ ) on total and progressive motility following dilution in Caprogen, BioXcell, and INRA96 was assessed on d $0,1,2$, and 3 postcollection. In experiment 1, semen stored in Caprogen, BioXcell, and INRA96 resulted in the highest total and progressive motility on d 1, 2, and 3 of storage compared with OptiXcell, BullXcell, NutriXcell, and AndroMed. In experiment 2, an effect of diluent on $\mathrm{CR}$ was found as semen diluted in BioXcell had a lower CR on d 1, 2, and 3 of storage $(46.3,35.4$, and $34.0 \%$, respectively) in comparison with Caprogen $(55.8,52.0$, and $51.9 \%$, respectively), INRA96 (55.0, 55.1, and 52.2\%, respectively), and frozen-thawed semen (59.7\%). Effects were found of parity, cow fertility sub-index, as well as the number of days in milk on CR. In experiment 3, when the storage temperature of diluted semen fluctuated between 4 and $18^{\circ} \mathrm{C}$, to mimic what occurs in the field (nighttime vs.

Received June 21, 2016.

Accepted October 3, 2016.

${ }^{1}$ Corresponding author: sean.fair@ul.ie daytime), BioXcell had the lowest total and progressive motility in comparison to Caprogen and INRA96. In conclusion, diluent significantly affected sperm motility when stored for up to $3 \mathrm{~d}$. Semen diluted in INRA96 resulted in a similar CR to semen diluted in Caprogen and to frozen-thawed semen, whereas that diluted in BioXcell resulted in a decreased CR. Consistent with this finding, semen diluted in BioXcell was less tolerant of temperature fluctuations than that stored in Caprogen or INRA96. Given that it can be used directly off the shelf, INRA96 may be a suitable alternative to Caprogen for the storage of liquid bull semen.

Key words: sperm, liquid semen, bovine, artificial insemination, calving rate

\section{INTRODUCTION}

Artificial insemination is the single most important technique devised to facilitate the genetic improvement of animals as it facilitates the widespread use of elite males (Black, 2006; Oliveira et al., 2013). Currently, within the Irish dairy industry, 95\% of AI is conducted using frozen-thawed semen, with liquid (i.e., fresh, noncryopreserved) semen accounting for only $5 \%$ of inseminations (Murphy et al., 2015). However, Ireland has a seasonal grass-based production system, and during the peak breeding season, from mid-April to early June, the use of liquid semen can increase to approximately $25 \%$ of inseminations to accommodate the large demand $(\mathrm{Al}$ Naib et al., 2011). In the Irish AI industry, a typical dose of liquid semen contains 5 million sperm (Murphy et al., 2013) in comparison to 15 to 20 million sperm for a typical frozen-thawed semen dose (Vishwanath et al., 1996). Liquid semen processing yields more doses per ejaculate, thereby, facilitating the greater utilization of genetically superior sires. This is particularly beneficial for young genomically selected sires as these sires are in high demand but produce lower semen volumes in comparison to more mature bulls (Brito et al., 2002). 
The extensive use of AI in the dairy industry can be partly attributed to the development of suitable diluents for both liquid and frozen-thawed semen (Foote, 2002). In Ireland, liquid semen is typically stored at ambient temperature in thermo-insulated containers to reduce the effects of the natural day to nighttime temperature fluctuations. Murphy et al. (2015) reported that although fluctuating storage temperature between 5 and $32^{\circ} \mathrm{C}$ had no effect on viability, total progressive motility was greatest for liquid semen stored at $15^{\circ} \mathrm{C}$ compared with other temperatures assessed. In addition to dilution of the semen, diluents provide protective compounds such as BSA, antioxidants, and antibiotics to maintain sperm function (Rehmana et al., 2013; van den Berg et al., 2014). Despite this, liquid semen has a limited shelf life and semen stored in Caprogen (the gold standard for liquid semen dilution) is principally used for only 2.5 to $3 \mathrm{~d}$ postcollection as a reduction in pregnancy rates has been reported thereafter (Vishwanath and Shannon, 2000). Several studies have been conducted on liquid bull semen diluents with the aim of combating the reduction in fertility associated with increased duration of storage (Vishwanath and Shannon, 2000; Verberckmoes et al., 2004; Murphy et al., 2015). Many of these studies have focused on reducing the metabolic activity of sperm cells as the survival of sperm for extended periods of time has been shown to be inversely related to their metabolic activity (Vishwanath and Shannon, 2000). Approaches taken have included storing semen at $5^{\circ} \mathrm{C}$ (Saha et al., 2014), reducing sperm concentration (Murphy et al., 2013), altering the $\mathrm{pH}$ (Ferdinand et al., 2014), as well as $\mathrm{N}_{2}$ gassing and modifying the diluent composition (Shannon, 1968). The ability to extend the shelf life of liquid semen is important as (1) the distribution of liquid semen would be simplified if it could be used for more days, and (2) the work load involved in collecting and processing semen would be greatly reduced as bulls used for liquid semen would have a reduced collection schedule.

Apart from Caprogen, several other diluents have been developed for the storage of semen for a variety of domestic species. BioXcell is an animal protein-free medium (soy lecithin-based extender), which has been routinely used for the cryopreservation and preservation at chilled temperatures of buffalo (Akhter et al., 2010, 2011), ram (Kulaksiz et al., 2012), and bull semen (Stradaioli et al., 2007). Although the benefits of using lecithin-based extenders on the cryopreservation of bull semen have been reported by several authors (van Wagtendonk-de Leeuw et al., 2000; Aires et al., 2003; Crespilho et al., 2014), many of these studies have focused on in vitro analysis only. INRA96 is a milk-based diluent that was primarily developed to maintain the fertility of stallion semen during chilled storage at 4 or at $15^{\circ} \mathrm{C}$ for up to $72 \mathrm{~h}$ (Batellier et al., 1997) but has also been used for the cryopreservation of equine semen (Fayrer-Hosken et al., 2008; Pillet et al., 2008). In recent years, INRA96 has also been used as a storage medium for the sperm of other species including rabbit (De Amicis et al., 2004), dog (Sahashi et al., 2011), goat (López-Fernández et al., 2011), and sheep (Olivera-Muzante et al., 2011) and has yielded acceptable fertility in vivo in sheep following cervical AI after $24 \mathrm{~h}$ of storage (O'Hara et al., 2010). Other commercially available extenders include OptiXcell, a protein-free egg yolk-like medium for frozen and liquid bull semen; NutriXcell, a long-term extender primarily used for the preservation of boar semen up to $6 \mathrm{~d}$ (Kaeoket et al., 2010); AndroMed, an egg-yolk-free, soy lecithin-based medium for freezing of bull (Maxwell et al., 2007), ram (Fukui et al., 2008), buffalo (Herold et al., 2004), and goat semen (Gacitua and Arav, 2005); and BullXcell, an egg-yolk Tris extender used for bull semen cryopreservation. Although all of the aforementioned diluents have been used for the preservation of semen from domestic species, many of these studies have solely reported in vitro data and there is a dearth of published studies on the in vivo fertility of bull semen stored in the majority of these diluents.

Using a combination of in vitro assessments and a large-scale commercial field trial, the objectives of this study were to assess the effect of (1) liquid semen diluent on total and progressive sperm motility, (2) liquid semen diluent on CR, and (3) temperature fluctuation of liquid semen on total and progressive motility of liquid bull semen. To our knowledge, this is the first report to examine the effect of a large number of diluents on liquid bull semen during in vitro storage, where each treatment was prepared from the same ejaculate. This eliminates any potential confounding effects arising from the collection of diluent treatments from different bulls or ejaculates and thus provides clear and reliable data.

\section{MATERIALS AND METHODS}

\section{Experiment 1: Storing Liquid Semen Maintained at a Constant Ambient Temperature}

Experimental Design. The aim of this experiment was to assess the ability of 7 liquid semen diluents (1 homemade and 6 commercially available) to sustain total and progressive motility of bull sperm for up to $3 \mathrm{~d}$ postcollection. Semen was collected from Holstein Friesian bulls $(\mathrm{n}=6)$ at a commercial AI center on 
3 different occasions (occasion $=$ replicate). The raw ejaculate was placed into a $50-\mathrm{mL}$ tube and transported in a temperature-regulated cooler box at $18^{\circ} \mathrm{C}$ to the laboratory (up to $3 \mathrm{~h}$ transport). On arrival, the ejaculate was assessed for weight, sperm concentration using a Coulter counter (Z Series, Beckman Coulter, Clare, Ireland), total motility (\%), and progressive motility on a 5 -point scale $(1=$ twitching/no forward progressive motility; $5=$ excellent forward progressive motile sperm) to ensure all semen samples were of a commercial standard. Microscopic assessments were conducted by the same technician and initial quality control cutoff values were a total and progressive motility of $\geq 70 \%$ and a score of $\geq 3$, respectively, and any ejaculates failing to meet these criteria were rejected.

The raw ejaculate was split and diluted to achieve a concentration of $5 \times 10^{6}$ sperm per $0.25-\mathrm{mL}$ insemination dose in 1 of 7 different diluents, namely Caprogen (homemade as per Vishwanath and Shannon 2000), OptiXcell (IMV Technologies, Normandy, France), BioXcell (IMV Technologies), BullXcell (IMV Technologies), INRA96 (IMV Technologies), NutriXcell (IMV Technologies), and AndroMed (Minitube, Tiefenbach, Germany). Prior to dilution, the Caprogen diluent was purged in food fresh nitrogen gas (BOC, Dublin, Ireland) as per standard preparation procedures to dispel oxygen from the media and create an anaerobic environment, limiting the metabolic activity of sperm during liquid storage (Vishwanath and Shannon, 2000). All other diluents were prepared as per the manufacturers' instructions. Semen from each bull was kept separate and ejaculates were split such that each bull was represented in each treatment. Semen straws were filled as per routine procedures and placed in a temperatureregulated cooler box at $18^{\circ} \mathrm{C}$. Samples from the different treatments were assessed in a randomized sequence to remove bias as a result of sampling order. Total and progressive motility; $\mathrm{n}=3$ replicates) were assessed in vitro on $\mathrm{d} 0,1,2$, and 3 postcollection ( $\mathrm{d} 0=4 \mathrm{~h}$ after collection). Within each replicate, on each assessment day, 2 straws from each bull $(\mathrm{n}=6)$ for each diluent (n $=7$ ) were assessed.

Assessment of Sperm Motility. Sperm motility (total and progressive) in liquid semen was assessed on d $0,1,2$, and 3 postsemen collection using a phase contrast microscope (CX31, Olympus, Centre Valley, PA) at a magnification of $400 \times$. A droplet of diluted semen $(5 \mu \mathrm{L})$ was placed on a pre-warmed glass slide, covered with a pre-warmed coverslip $\left(37^{\circ} \mathrm{C}\right)$, and assessed by counting a minimum of 100 sperm, over at least 5 different fields of view, for each treatment on each assessment day. Total motility was expressed as a percentage of the total sperm population (motile and nonmotile). A sperm was deemed to display progressive motility if it moved in a linear fashion; progressive motility was expressed as the percentage of live and motile sperm that displayed forward progressive motion.

\section{Experiment 2: Field Fertility of Liquid Semen Diluted in Caprogen, BioXcell, and INRA96}

Experimental Design. The aim of this experiment was to assess the effect of 3 liquid semen diluents, selected based on the outcome of experiment 1, on CR following AI. Semen was collected from Holstein Friesian bulls $(\mathrm{n}=8$; denoted $\mathrm{A}-\mathrm{H})$ at a commercial AI center from early May to the end of May 2015. There were 11 collection days in total, with 2 bulls used per collection day (total of 22 ejaculates). Following assessment for volume, concentration, and motility (as described in experiment 1), each acceptable ejaculate was split into 3 equal volumes and diluted directly to a final concentration of $5 \times 10^{6}$ sperm per $0.25-\mathrm{mL}$ insemination dose in 1 of 3 diluents; namely, Caprogen, BioXcell, or INRA96 (Figure 1). All 3 diluents were prepared as per experiment 1. Each batch of liquid semen was clearly labeled and distributed for insemination on the day of collection. Liquid semen was used for up to $3 \mathrm{~d}$ postcollection on both heifers $(\mathrm{n}=192)$ and multiparous $(\mathrm{n}=9,611)$ dairy cows. Due to logistical constraints, frozen-thawed semen doses were derived from previously collected ejaculates from the same 8 bulls, which were processed and frozen using routine procedures ( $\mathrm{n}=9,323$ inseminations consisting of 526 heifers and 8,797 multiparous dairy cows). Upon collection of semen samples for cryopreservation, the raw ejaculate was partially diluted in $10 \mathrm{~mL}$ of pre-warmed BullXcell $\left(37^{\circ} \mathrm{C}\right)$. Semen samples were assessed for volume, sperm concentration, and total and progressive motility as described in experiment 1 . Only ejaculates achieving a total motility score of $\geq 70 \%$ and a progressive motility score of $\geq 3$ were used for cryopreservation. Following in vitro assessments, the semen was fully extended with pre-warmed BullXcell to achieve a concentration of 15 $\times 10^{6}$ sperm per $0.25-\mathrm{mL}$ insemination dose. Straws were frozen to $-140^{\circ} \mathrm{C}$ as follows: $-5^{\circ} \mathrm{C}$ per min from +4 to $-10^{\circ} \mathrm{C},-40^{\circ} \mathrm{C}$ per min from -10 to $-100^{\circ} \mathrm{C}$ and thereafter $-20^{\circ} \mathrm{C}$ per min from -100 to $-140^{\circ} \mathrm{C}$ in a programmable freezer (IMV Technologies), followed by submersion and storage in liquid nitrogen at $-196^{\circ} \mathrm{C}$ until use.

Field Inseminations. Inseminations were carried out in May 2015 (coinciding with the peak dairy breeding season) in Irish dairy herds $(\mathrm{n}=2,490)$. The majority of inseminations were in Holstein Friesian cows $(\mathrm{n}=$ 18,304 ), but small numbers of cows of other breeds were 


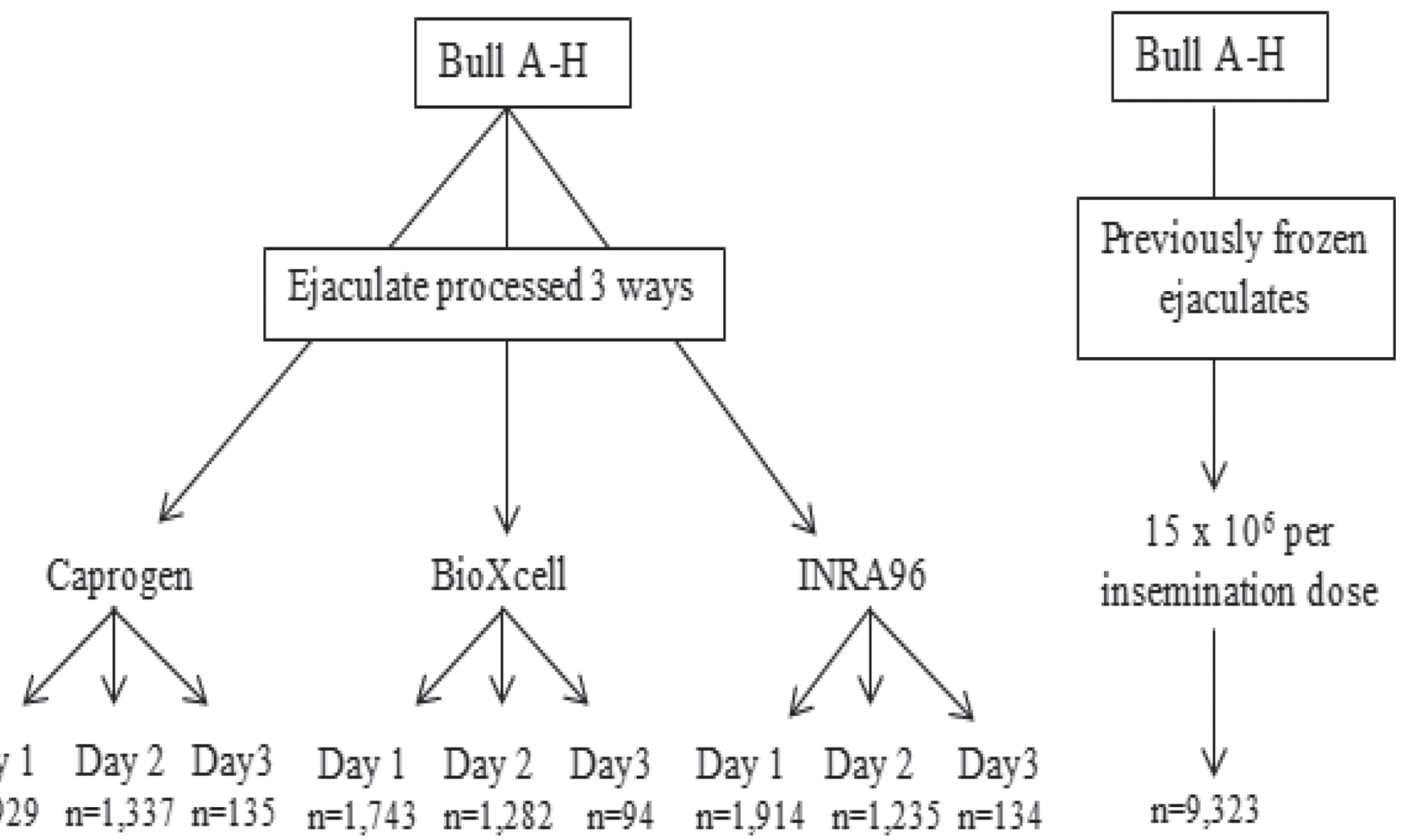

Figure 1. Experimental design for experiment 2. Ejaculates were split for the liquid semen treatments, and previously frozen ejaculates from the same bull were sourced for the frozen-thawed treatment $(\mathrm{n}=$ the total number of inseminations per diluent per day). Caprogen (homemade as per Vishwanath and Shannon, 2000), BioXcell (IMV Technologies, Normandy, France), and INRA96 (IMV Technologies).

represented: Jersey $(\mathrm{n}=375)$, Montbeliarde $(\mathrm{n}=113)$, Norwegian Red $(\mathrm{n}=268)$, Swedish Red cows $(\mathrm{n}=10)$, and other $(\mathrm{n}=56$; includes Normande, Rotbunte, Danish Red, and Red Poll). Technicians $(\mathrm{n}=108)$ were grouped into geographical areas and treatments were rotated on each collection day to ensure that technicians received different diluent treatments from each of 2 bulls on each day (Figure 2). Technicians were blind to treatments. For each insemination, the AI technician recorded the bull code, cow tag number, and straw code on a handheld electronic device. Insemination and $\mathrm{CR}$ data were captured using the Irish Cattle Breeding Federation (Bandon, Co. Cork, Ireland) database by cross-referencing the technician name with the bull code and semen type used on each date within the trial period. Obvious errors were extracted from the data set and data were then interrogated to remove animals based on the following criteria: cows which were not at first AI, cows which received 2 inseminations from 2 different bulls or diluent treatments, or cows that were not of a dairy breed. However, if a cow received 2 inseminations from the same bull with the same diluent treatment within $5 \mathrm{~d}$ of each other, the record was kept and the second date was assumed to be correct. Postediting, a total of 19,126 inseminations remained. The CR was measured using a cut-off value of 275 and $290 \mathrm{~d}$ from the date of insemination to calving date.

\section{Experiment 3: Effect of Temperature Fluctuations on Semen}

Based on the outcome of experiment 2, we hypothesized that the effect of fluctuating temperatures experienced in practice during storage of liquid semen would be different for semen diluted in Caprogen, BioXcell, and INRA96. Semen was collected from Holstein Friesian bulls $(\mathrm{n}=6)$ at a commercial AI center on 3 occasions (occasion $=$ replicate). Semen from each bull was kept separate and ejaculates were assessed and diluted in Caprogen, BioXcell, and INRA96 (as per experiment 2 ). After packaging, straws were placed in a polystyrene box and stored at $18^{\circ} \mathrm{C}$ during the day and gradually brought to $4^{\circ} \mathrm{C}$ during the night to mimic the unregulated temperature fluctuations to which liquid semen is typically subjected when stored in thermo-insulated containers in practice (Murphy et al., 2015). Samples 
from the different treatments were assessed on d 0,1 , 2 , and 3 postcollection in a randomized sequence to remove bias as a result of sampling order. Total and progressive motility was assessed in vitro as described in experiment 1 using a computer-assisted sperm analyzer (IVOS II, IMV Technologies).

\section{Statistical Analysis}

Data from experiments 1 and 3 were examined for normality of distribution and homogeneity of variance and analyzed using the general linear model (GLM) repeated-measures procedure with a compound sym-

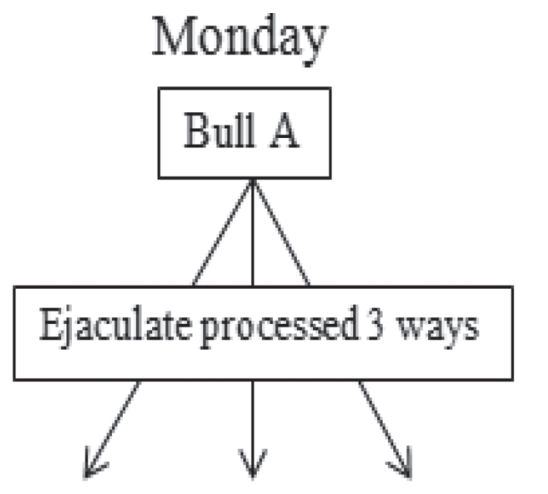

Caprogen BioXcell INRA96<smiles>C[Te]</smiles>

Tech. Tech. Tech.

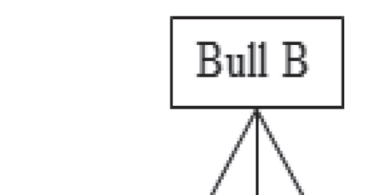

Ejaculate processed 3 ways

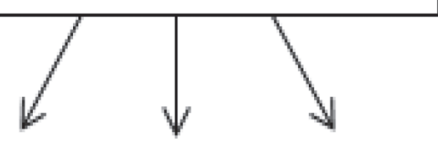

Caprogen BioXcell INRA96

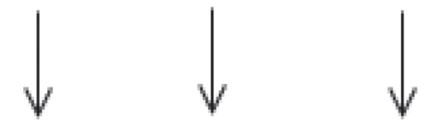

Tech. Tech. Tech.
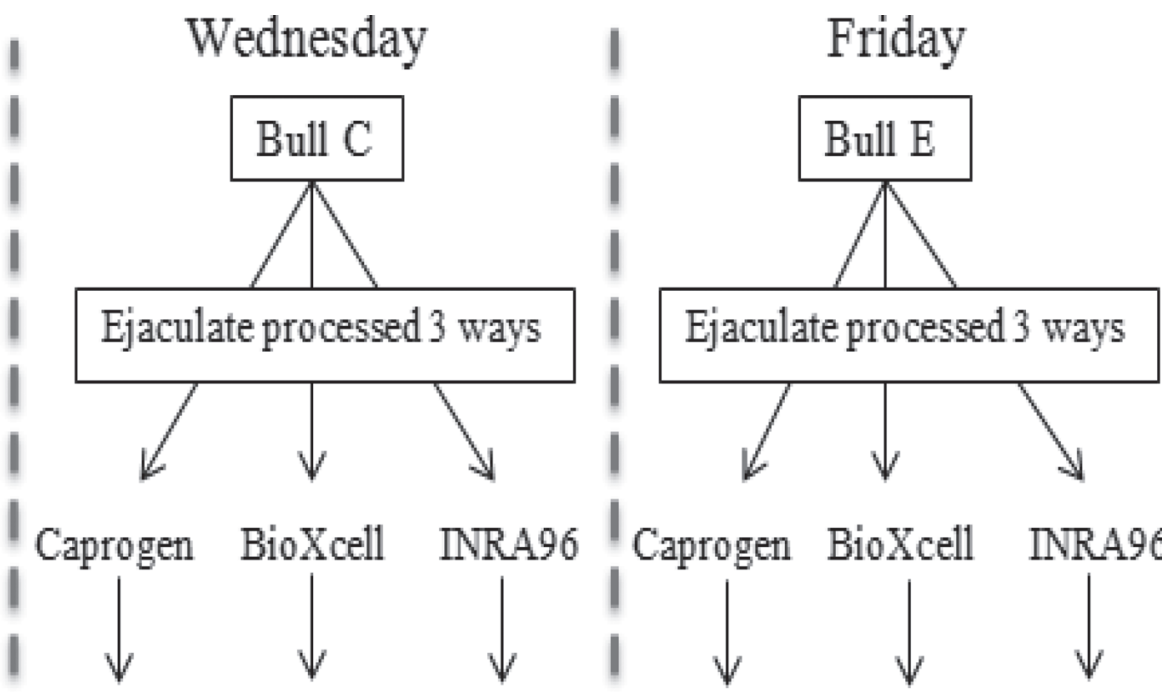

Tech. Tech. Tech.
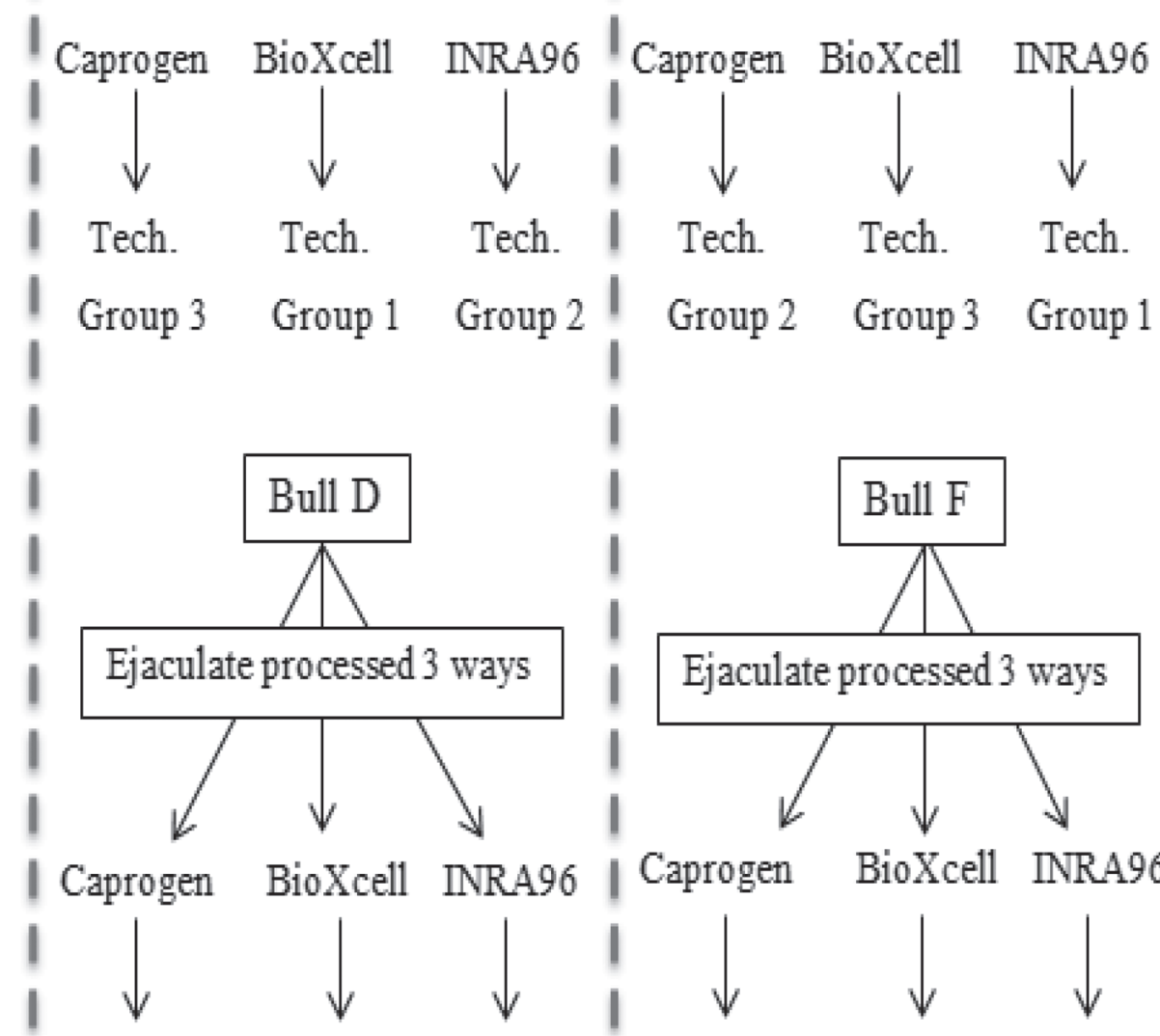

Tech.

Tech.

Tech.
Tech.

Group 2 Group 3 Group 1
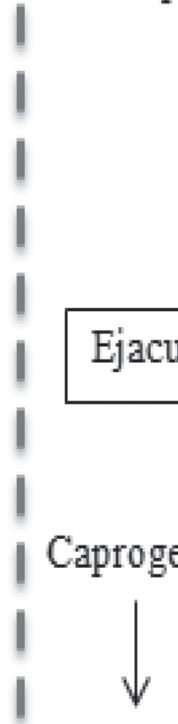

Ejaculate processed 3 ways

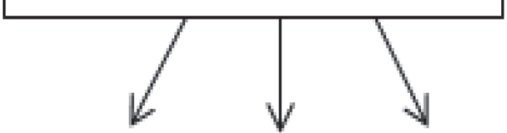

BioXcell INRA96

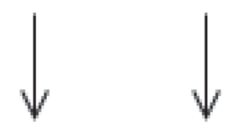

Tech.

Tech. Tech.
| Caprogen

\section{Group 2 Group 3 Group 1 I Group 1 Group 2 Group 3 I Group 3 Group 1 Group 2}

Figure 2. Experimental design for experiment 2, highlighting the distribution of different liquid semen treatments to technicians within a week (displaying bulls A-F only). Each technician received 2 different treatments each day. Frozen-thawed semen was also inseminated throughout the period. Caprogen (homemade as per Vishwanath and Shannon, 2000), BioXcell (IMV Technologies, Normandy, France), INRA96 (IMV Technologies). 
metry covariance structure in Statistical Package for Social Science (SPSS, version 22.0, IBM, Chicago, IL). The final model included the main effects of diluent treatment, day, and their interaction. In experiment 2, the CR data from the field trial were assessed using Pearson's chi-squared procedure in SPSS to compare CR between diluent treatments. Data were cross checked using an ANOVA model. The dependent variable in the analysis was $\mathrm{CR}(1=$ calved, $0=$ not calved). In addition, using a general linear model for binomial data $\mathrm{CR}$ was evaluated and correlations were investigated with several fixed effects, namely, diluent treatment, bull, parity number, cow breed, cow fertility sub-index, DIM, herd, and technician. Each fixed effect was assessed for an interaction with diluent treatment. All post-hoc tests were carried out using the Bonferroni test and results are reported as the mean \pm the standard error of the mean in experiments 1 and 3 and as the estimated marginal mean in experiment 2 , to adjust for imbalance between the number of inseminations in each treatment. Data were considered to differ significantly at $P<0.05$.

\section{RESULTS}

\section{Experiment 1: Storing Liquid Semen Maintained at a Constant Ambient Temperature}

An effect was observed of diluent $(P<0.01)$ and day $(P<0.05)$ on both total and progressive motility; from d 0 to 3 across all treatments the percentage of motile sperm declined linearly. No diluent by day interaction $(P>0.05)$ was found. Caprogen, BioXcell, and INRA96 maintained d 3 sperm total motility (64.0 $\pm 2.66,58.5 \pm 2.83$, and $58.0 \pm 2.35 \%$, respectively) and progressive motility $(59.2 \pm 3.18,47.5 \pm 2.36$, and $56.8 \pm 1.59 \%$, respectively) at the highest levels. Sperm stored in BullXcell and AndroMed had intermediate total and progressive motility scores, whereas NutriXcell and OptiXcell had the lowest total and progressive motility on d 3, respectively (Figure 3).

\section{Experiment 2: Field Fertility of Liquid Semen Diluted in Caprogen, BioXcell, and INRA96}

Effect of Diluent on Calving Rate. Overall, insemination with liquid semen on d 1, 2, and 3 postcollection resulted in a lower CR $(52.7,47.3$, and $47.5 \%$, respectively) in comparison to frozen-thawed semen $(59.7 \%, P<0.01$; Figure 4). However, this was attributed to the poor CR recorded for BioXcell on d 1,2, and 3 of storage, as semen diluted in Caprogen and INRA96 and stored for up to $3 \mathrm{~d}$ had a similar CR compared with frozen-thawed semen. Semen diluted in BioXcell had a lower CR following storage for 1,2 , or $3 \mathrm{~d}$ after collection in comparison with Caprogen, INRA96, and frozen-thawed semen $(P<0.01$; Figure 5$)$.

Effect of Bull on Calving Rate. An effect was observed of bull on $\mathrm{CR}(P<0.01)$ with the CR for individual bulls varying from 54.7 to $67.3 \%$. A bull by day interaction $(P<0.01)$ was observed, represented by bulls $\mathrm{B}$ and $\mathrm{D}$ having a higher $\mathrm{CR}$ on $\mathrm{d} 1$ than liquid semen on d $2(P<0.05)$ but did not differ from d 3 ( $P$ $>0.05)$. Bull $\mathrm{F}$ had a higher $\mathrm{CR}$ for liquid semen on d 1 than liquid semen on $\mathrm{d} 3(P<0.05)$ but did not differ from liquid semen inseminated on d $2(P>0.05)$. Although mean CR following AI with liquid semen on d 2 was reduced in comparison to d 1 in all bulls with the exception of bull $\mathrm{E}$, this reduction was only statistically significant in 2 bulls (B and D; Table 1). However, bulls $B$ and $G$ had a higher CR when frozen-thawed semen was used in comparison to liquid semen on $\mathrm{d} 1$ and 2 , respectively $(P<0.01$ : Table 1$)$, but this was primarily a result of the poor CR recorded for BioXcell.

Effect of Cow Characteristics, Herd, and Technician on Calving Rate. An effect was found of parity, cow fertility sub-index, and DIM on CR ( $P$ $<0.01)$. The $\mathrm{CR}$ varied between individual herds and technicians, for herds and technicians with greater than 20 and 100 recorded inseminations, respectively $(P<0.01)$. A parity by diluent treatment interaction was found but with no clear biological pattern $(P<$ $0.01)$. A cow fertility sub-index by treatment interaction $(P<0.01)$ was observed as the CR of cows and heifers inseminated with BioXcell, INRA96, and frozenthawed semen increased with increasing cow fertility sub-indexes, whereas this trend was present but not statistically significant for semen diluted in Caprogen (Figure 6). No effect was found of breed or a breed, herd, or technician by diluent interaction $(P>0.05)$.

\section{Experiment 3: Effect of Temperature Fluctuations on Semen}

When temperature was fluctuated, diluent $(P<$ $0.01)$ and day $(P<0.01)$ had an effect on both total and progressive motility. Semen stored in Caprogen and INRA96 recorded a greater total and progressive motility score than BioXcell $(P<0.01)$ but did not differ from each other $(P>0.05$; Figure 7$)$. From $d$ 0 to 3 across all treatments, the percentage of sperm displaying total and progressive motility declined linearly, but no diluent by day interaction was found $(P>$ 0.05). Fluctuation of temperature between 4 and $18^{\circ} \mathrm{C}$ was detrimental to motility of sperm stored in BioXcell as both total and progressive motility declined with increased duration of storage from $62.3 \pm 4.61$ to 37.4 $\pm 10.0 \%$, and $54.4 \pm 18.7$ to $35.4 \pm 10.2 \%$, respectively, 

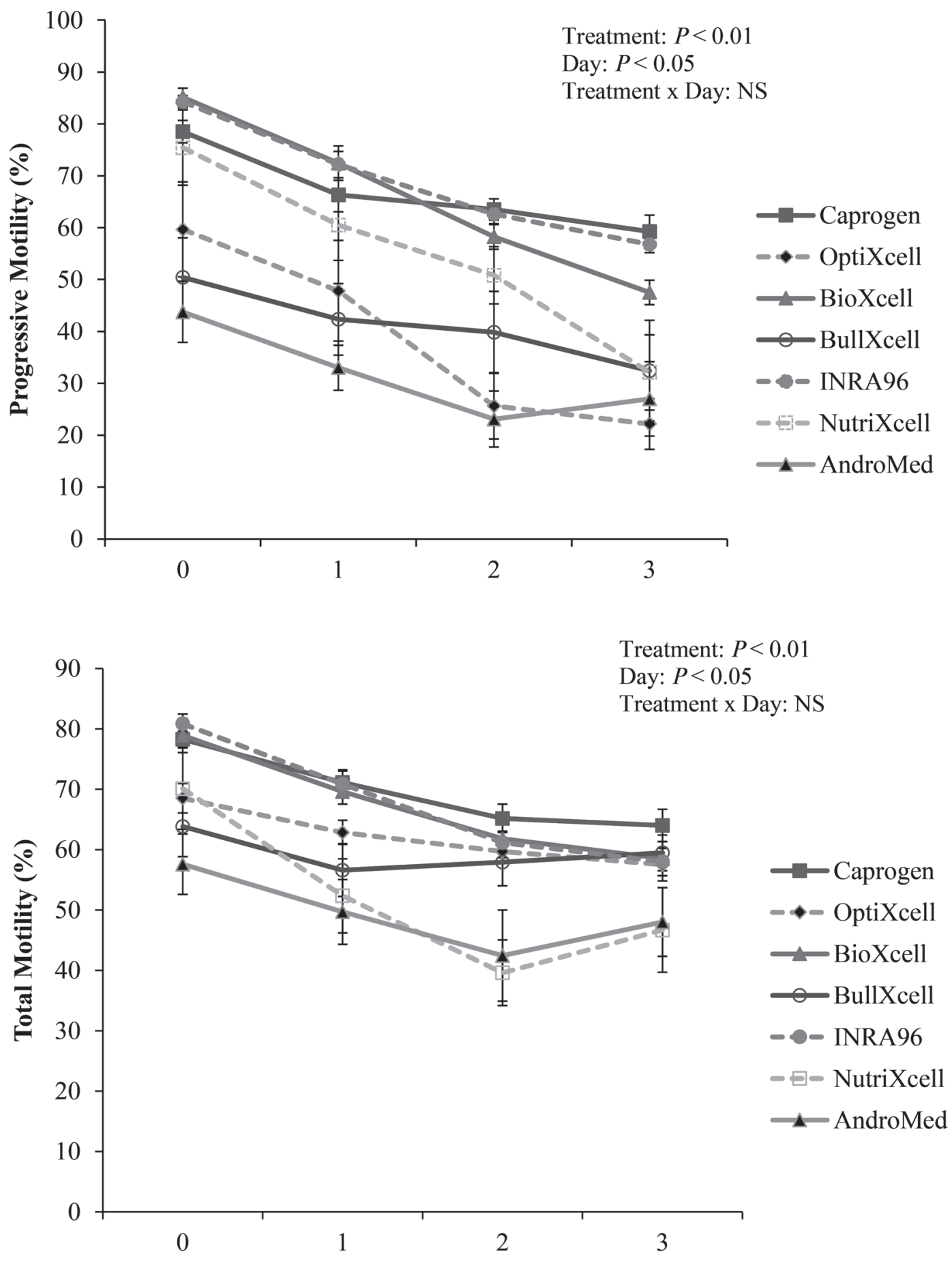

Day Post Collection

Figure 3. The effect of diluent on progressive motility (upper panel) and total motility (lower panel) of liquid bull semen on d $0,1,2$, and 3 postcollection (experiment 1). Vertical bars represent SEM. Caprogen (homemade as per Vishwanath and Shannon, 2000), OptiXcell (IMV Technologies, Normandy, France), BioXcell (IMV Technologies), BullXcell (IMV Technologies), INRA96 (IMV Technologies), NutriXcell (IMV Technologies), and AndroMed (Minitube, Tiefenbach, Germany). 


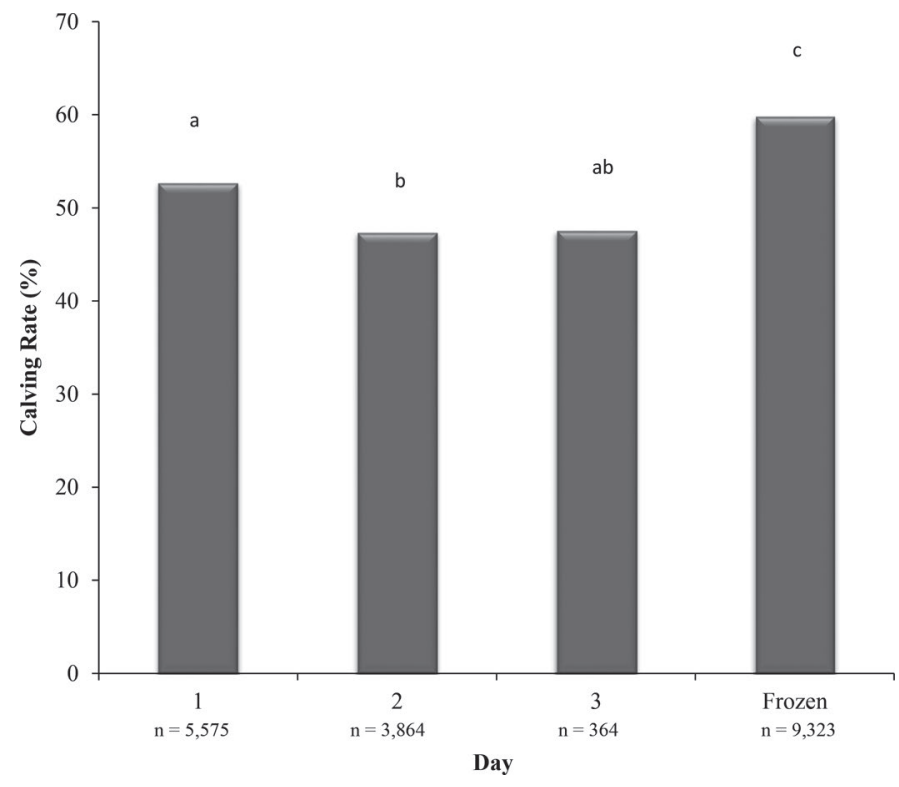

Figure 4. The effect of day of storage of liquid bull semen on calving rate in dairy cows and heifers (experiment 2). Values with different superscripts differ significantly $(P<0.01)$. from d 0 to 3 of storage. Sperm stored in Caprogen and INRA96 maintained total $(65.7 \pm 1.98$ and 65.7 $\pm 5.02 \%$, respectively) and progressive motility (52.5 $\pm 3.58 \%$ and $59.6 \pm 5.04 \%$, respectively) up to $3 \mathrm{~d}$ of storage (Figure 7).

\section{DISCUSSION}

Despite the importance of AI to the dairy industry, there is a dearth of published studies comparing the field fertility of semen stored in different diluents. We have taken the approach of using split ejaculates and a combination of in vitro and in vivo assessments in a comprehensive attempt to identify the optimal semen diluent for liquid bull semen. The main findings of this study were that (1) liquid semen diluted in Caprogen or INRA96 resulted in a similar CR to frozen-thawed semen; (2) liquid semen stored in BioXcell resulted in a reduced CR in comparison to semen diluted in Caprogen or INRA96 and frozen-thawed semen; and (3) temperature fluctuation between 4 and $18^{\circ} \mathrm{C}$ was detrimental to sperm motility when diluted in BioXcell but not in Caprogen or INRA96.

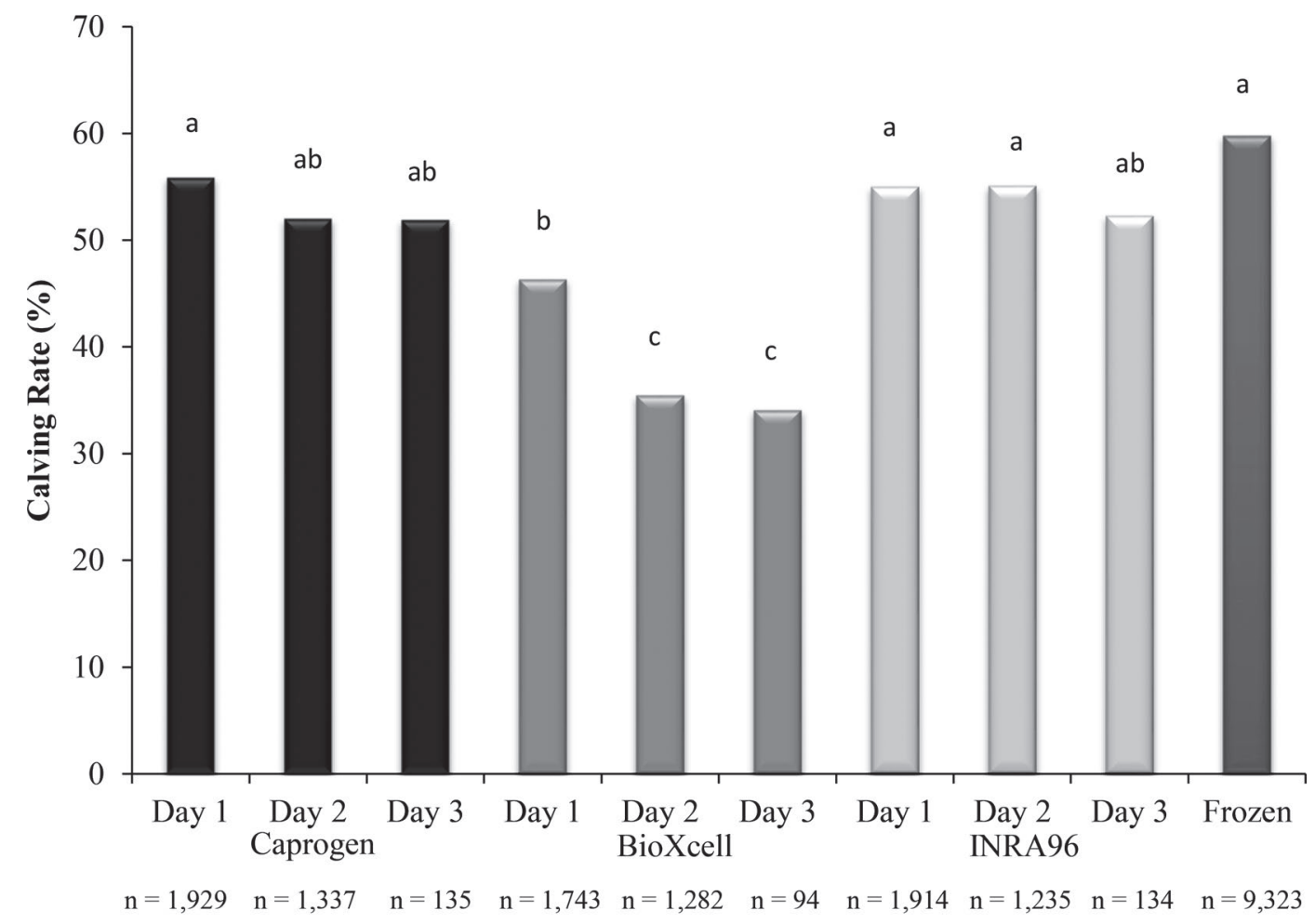

Semen Treatment

Figure 5. The effect of liquid semen diluent and day of storage on calving rate in dairy cows and heifers (experiment 2). Values with different superscripts differ significantly $(P<0.01)$. Caprogen (homemade as per Vishwanath and Shannon, 2000), BioXcell (IMV Technologies, Normandy, France), and INRA96 (IMV Technologies). 
Table 1. The effect of liquid bull semen inseminated on d 1,2, or 3 postcollection and frozen-thawed semen on calving rate in dairy cows and heifers (experiment 2)

\begin{tabular}{|c|c|c|c|c|}
\hline Bull & $\begin{array}{l}\text { Liquid d } 1, \\
\% \text { calving rate (n) }\end{array}$ & $\begin{array}{l}\text { Liquid d } 2, \\
\% \text { calving rate (n) }\end{array}$ & $\begin{array}{l}\text { Liquid d 3, } \\
\% \text { calving rate (n) }\end{array}$ & $\begin{array}{l}\text { Frozen-thawed, } \\
\% \text { calving rate (n) }\end{array}$ \\
\hline $\mathrm{A}$ & $\begin{array}{c}53.3 \\
(880)\end{array}$ & $\begin{array}{c}47.2 \\
(697)\end{array}$ & 46.2 & $\begin{array}{r}51.9 \\
(376)\end{array}$ \\
\hline \multirow[t]{2}{*}{ B } & $53.4^{\mathrm{a}}$ & $47.4^{\mathrm{b}}$ & $73.1^{\mathrm{abc}}$ & $\begin{array}{r}(36 \mathrm{~b}) \\
60.0^{\mathrm{c}}\end{array}$ \\
\hline & $(1,836)$ & $(1,453)$ & (26) & $(1,106)$ \\
\hline \multirow[t]{2}{*}{$\mathrm{C}$} & 55.1 & 52.2 & 68.4 & 64.4 \\
\hline & (234) & (113) & (19) & (877) \\
\hline \multirow[t]{2}{*}{$\mathrm{D}$} & $52.3^{\mathrm{a}}$ & $41.5^{\mathrm{b}}$ & $54.6^{\mathrm{ab}}$ & $57.7^{\mathrm{a}}$ \\
\hline & (457) & (415) & (11) & $(2,593)$ \\
\hline \multirow[t]{2}{*}{$\mathrm{E}$} & $44.4^{\mathrm{a}}$ & $51.1^{\mathrm{a}}$ & $43.9^{\mathrm{a}}$ & $61.3^{\mathrm{b}}$ \\
\hline & (531) & (276) & (139) & $(741)$ \\
\hline \multirow[t]{2}{*}{$\mathrm{F}$} & $54.8^{\mathrm{a}}$ & $47.9^{\mathrm{ab}}$ & $42^{b}$ & $59.8^{\mathrm{a}}$ \\
\hline & $(765)$ & $(386)$ & $(150)$ & (801) \\
\hline \multirow[t]{2}{*}{ G } & $34.2^{\mathrm{a}}$ & $36.8^{\mathrm{a}}$ & 0 & $61.1^{\mathrm{b}}$ \\
\hline & (79) & (57) & $(0)$ & $(2,272)$ \\
\hline \multirow[t]{2}{*}{$\mathrm{H}$} & $54.9^{\mathrm{ab}}$ & $50.1^{\mathrm{a}}$ & $83.3^{\mathrm{ab}}$ & $59.4^{\mathrm{b}}$ \\
\hline & $(793)$ & $(467)$ & (6) & $(557)$ \\
\hline \multirow[t]{2}{*}{ Overall } & $52.6^{\mathrm{a}}$ & $47.3^{\mathrm{b}}$ & $47.5^{\mathrm{ab}}$ & $59.7^{\mathrm{c}}$ \\
\hline & $(5,575)$ & $(3,864)$ & $(364)$ & $(9,323)$ \\
\hline
\end{tabular}

${ }^{a-c}$ Values in the same row with different superscripts differ significantly $(P<0.01)$.

Regardless of storage temperature, sperm motility, and thus fertility, declines over an extended period of time (Vishwanath and Shannon, 2000; Akhter et al., 2011). In agreement, the results of this study demonstrated that irrespective of semen extender, semen quality, measured in terms of total and progressive motility, declined with increased duration of storage. When liquid semen was stored at a constant temperature, Caprogen, BioXcell, and INRA96 maintained better total and progressive motility than AndroMed,

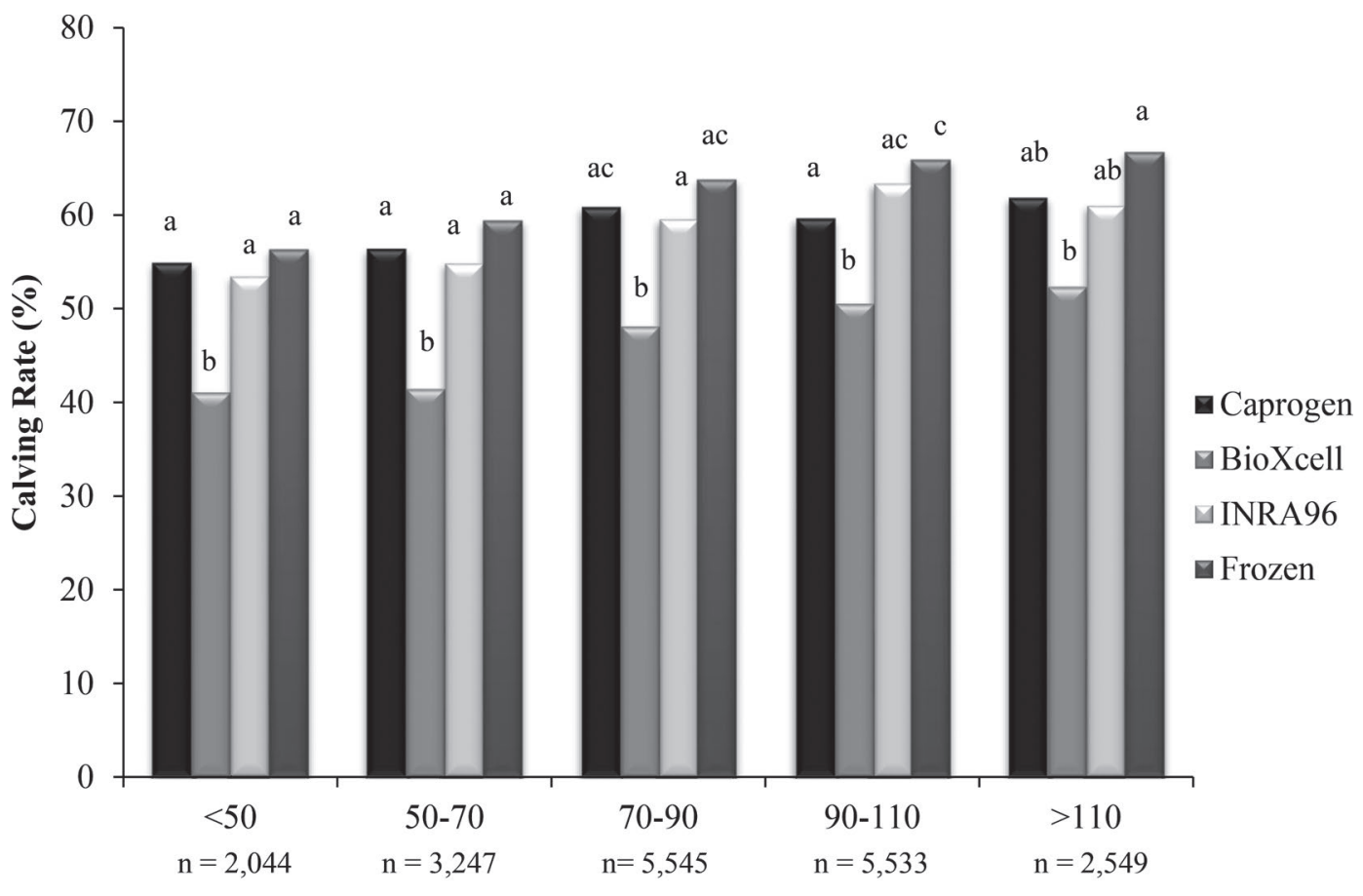

Cow Fertility Sub-Index (€)

Figure 6. The effect of cow fertility sub-index by treatment interaction on calving rate in dairy cows and heifers (experiment 2). Values with different superscripts differ significantly within fertility sub-indices $(P<0.01)$. Caprogen (homemade as per Vishwanath and Shannon, 2000), BioXcell (IMV Technologies, Normandy, France), and INRA96 (IMV Technologies). 

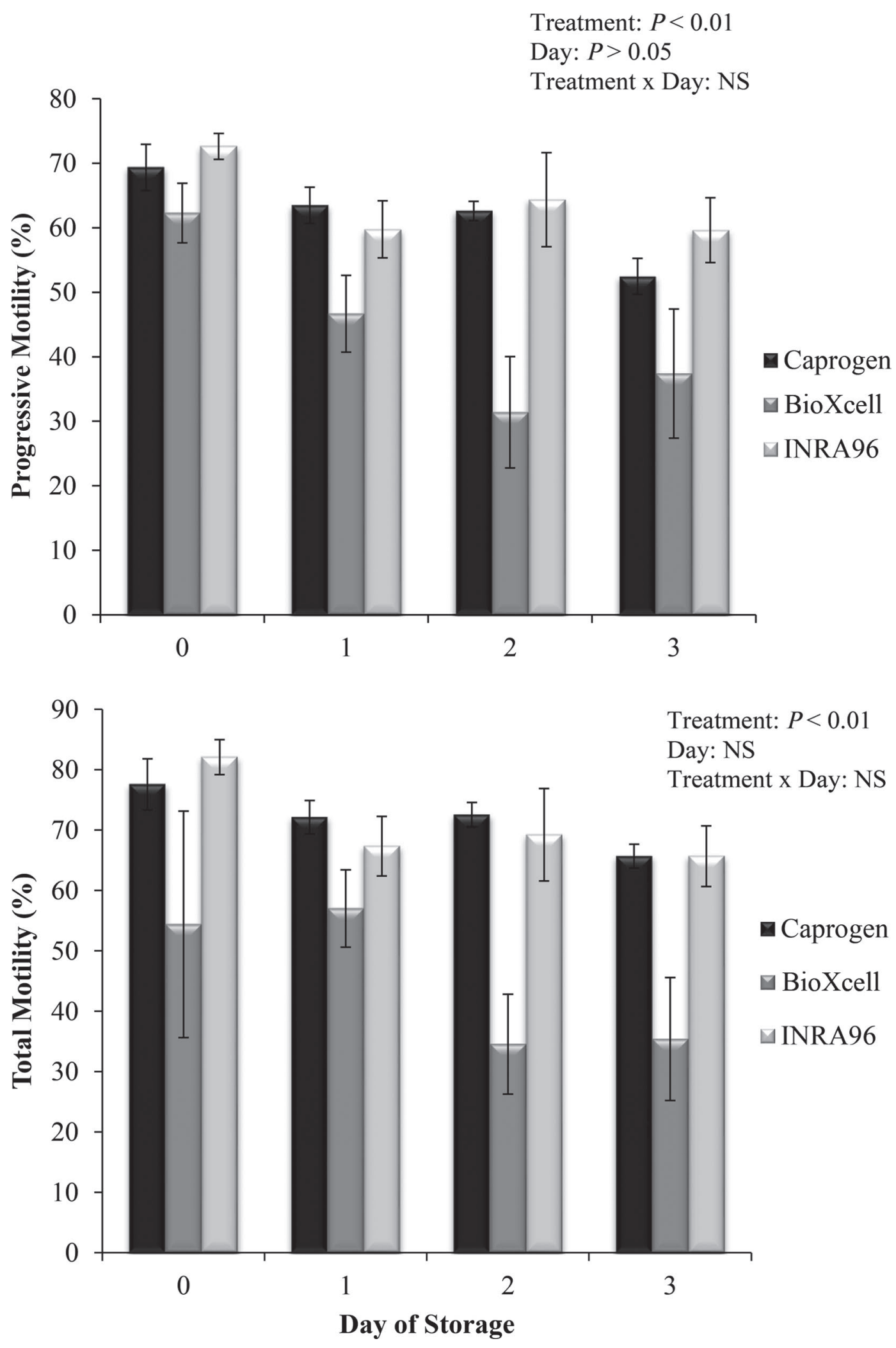

Figure 7. The effect of temperature fluctuation on progressive motility (upper panel) and total motility (lower panel) of liquid bull semen stored in 3 diluents and assessed on d 0,1,2, and 3 postcollection (experiment 3). Vertical bars represent SEM. Caprogen (homemade as per Vishwanath and Shannon, 2000), BioXcell (IMV Technologies, Normandy, France), and INRA96 (IMV Technologies). 
BullXcell, NutriXcell, and OptiXcell. Caprogen, the industry standard liquid bull semen diluent, although initially developed for the dilution of semen at $5^{\circ} \mathrm{C}$ (Shannon 1965), has been shown to maintain sperm motility for extended periods and result in higher fertility rates when stored at an ambient temperature of $18^{\circ} \mathrm{C}$ (Shannon et al., 1984). The results of this study support this finding as Caprogen resulted in the highest total motility score on d 3 of storage when stored at ambient temperature. INRA96, although not primarily used for the preservation of bull semen, performed well in comparison to Caprogen and had the highest total and progressive motility score when temperatures were fluctuated between 4 and $18^{\circ} \mathrm{C}$. O'Hara et al. (2010) reported that storing ram semen in INRA96 at a constant $15^{\circ} \mathrm{C}$ resulted in significantly reduced sperm motility but when stored at a constant $5^{\circ} \mathrm{C}$ INRA96 performed well both in terms of in vitro and in vivo fertility. In the current study, INRA96 recorded the second highest and highest total and progressive motility score, respectively, on d 3 compared with the other diluents when semen was stored at a constant temperature of $18^{\circ} \mathrm{C}$.

BioXcell (soy lecithin-based extender) has been used routinely as a cryopreservation medium for buffalo, ram, and bull semen, and several studies have compared its use on frozen-thawed semen against other commercially available diluents in these species (Gil et al., 2003; Stradaioli et al., 2007; Sharafi et al., 2009; Chaudhari et al., 2015). Both Gil et al. (2003) and Sharafi et al. (2009) reported a lack of difference in motility and capacitation status between ram semen diluted in BioXcell and the control extender (L1G7 and milk-egg yolk based extender, respectively). Similarly, Gil et al. (2003) reported no difference in fertility, suggesting that although BioXcell did not improve sperm quality in vitro or in vivo it could offer a safer alternative to preserving ram semen due to the reduced health risk associated with animal protein-free media. Stradaioli et al. (2007) reported BioXcell to be superior in preserving post-thaw bull sperm motility as well as lowering the proportion of acrosome-reacted and capacitated sperm in comparison to a traditional egg-yolk Tris glycerol extender. An in vitro study on liquid stored buffalo semen by Akhter et al. (2011) demonstrated that semen quality parameters for BioXcell were comparable to both milk and egg-yolk-based extenders up to d 3 of storage but were higher for BioXcell on d 5 when semen was stored at a constant temperature of $5^{\circ} \mathrm{C}$ (the manufacturer's recommended storage temperature of fresh semen diluted in BioXcell). Kasimanickam et al. (2011) stated that soy-based extenders had similar protection capabilities in liquid ram semen as an egg-yolk extender and were superior to liquid semen diluted in a milk-based diluent. In contrast to these studies, in the current study, although BioXcell performed well up to d 3 of storage when maintained at a constant ambient temperature, the in vivo fertility results were inferior to those recorded by both Caprogen and INRA96.

The reduction in fertility associated with BioXcell observed in this study would indicate that BioXcell is less tolerant of temperature fluctuations and thus would not be a suitable substitute for an egg-yolk or milk-based extender if liquid semen was subjected to temperature variations. One possible explanation for this reduction is that as semen temperature fluctuates, morphological membrane changes consistent with a lipid phase transition occurring (Drobnis et al., 1993). This results in compacting or relaxing the packing of the phospholipid bilayer, causing membrane destabilization and ultimately cell death (Crowe et al., 1990). Thus, maintaining semen at a constant ambient temperature results in regulating this transition phase and reduces the damage sustained to sperm cells (Crowe et al., 1998). As well as this, a family of lipid-binding proteins (bovine seminal plasma proteins; BSP) found in seminal plasma are among the principal causes of damage to sperm cells during storage (Bergeron and Manjunath, 2006). It is believed that low density lipoproteins found in egg-yolk and casein micelles found in milk interact with BSP proteins to reduce the lipid loss from the sperm membrane, thus stabilizing the membrane and maintaining sperm function during storage (Bergeron et al., 2007; Lusignan et al., 2011; Manjunath, 2012). These low-density lipoproteins are also believed to be important in protecting sperm cells during the lipid phase transition (Holt, 2000) and as the protective action of casein micelles on sperm is thought to be analogous to the protective action of lipoproteins in egg yolk (Bergeron et al., 2007), it could be postulated that casein micelles are the effective component in milk-based diluents also protecting cells from the damage arising from the lipid phase transition.

Caprogen and INRA96 resulted in similar CR, suggesting that both diluents are capable of efficiently protecting the sperm membrane from excessive BSP protein binding, which results in the loss of cholesterol and phospholipids, resulting in a deleterious effect on sperm function (Bergeron and Manjunath, 2006). The results also highlight that both Caprogen and INRA96 are efficient at maintaining sperm quality when semen is stored at either a constant or fluctuating temperature, suggesting that they are both capable of stabilizing the sperm membrane during the lipid phase transition. BioXcell displayed an ability to protect sperm cells when semen was stored at a constant temperature; however, during temperature fluctuations its protection was inferior to both Caprogen and INRA96, as evidenced by a reduction of approximately 30 and 
$20 \%$ in total and progressive motility on d 3 of storage, respectively, in comparison to Caprogen and INRA96. The reason for this is unclear, but as soy lecithin (a plant source) is used in animal-protein free medium to substitute for the phospholipids in egg yolk and casein micelles in milk-based diluents, plant-based diluents may be less efficient in protecting sperm cells from temperature variations. Further research is required to understand the exact mechanisms of protection offered to sperm cells by BioXcell.

AndroMed, also a soy-lecithin-based extender, has been reported to result in better postthaw sperm quality than milk-based extenders in the goat (JiménezRabadán et al., 2012), yielded similar pregnancy rates in frozen-thawed semen compared with an egg-yolk extender in the ram (Fukui et al., 2008) and resulted in higher nonreturn rates in frozen-thawed semen when compared with a Tris-egg-yolk-based extender in the bull (Aires et al., 2003). de Paz et al. (2010) reported that liquid ram semen diluted in a soybean lecithin extender maintained higher sperm motility and viability at 5 and $15^{\circ} \mathrm{C}$ of storage in comparison to a control egg-yolk extender. These studies suggest that a soy lecithin-based extender can be just as effective in preserving semen, if not better, than egg-yolk and milkbased diluents. In the current study, however, semen diluted in AndroMed performed poorly in comparison to the egg yolk (Caprogen) and milk-based (INRA96) diluent used for liquid semen in this study. BullXcell is used routinely in the cryopreservation of bull semen and performed adequately when storing liquid semen at a constant temperature. However, Caprogen resulted in superior semen quality in terms of total and progressive motility in comparison to BullXcell. NutriXcell, which is primarily used for the preservation of boar semen, and OptiXcell, a protein-free egg-yolk-like diluent, were the least effective extenders in maintaining total and progressive motility of bull semen, respectively, when stored at a constant ambient temperature. Although these extenders have been used for the preservation of sperm from several species, limited data have been published investigating their use against other diluents using bull semen.

In the current study, sperm were stored at 5 million per dose in all treatments compared with 1 to 2 million sperm, which are reported to be the norm in New Zealand (Vishwanath and Shannon, 2000). It is acknowledged that sperm metabolic activity is inversely related to extended sperm survival (Vishwanath and Shannon, 2000) and that higher sperm numbers during storage of liquid semen results in increased oxidative stress due to the production of reactive oxygen species (ROS; Murphy et al., 2013). The addition of components such as citric acid, catalase, and glycerol in a wide range of diluents play a role in reducing the levels of peroxide generated in the storage medium. Other unique factors such as the use of nitrogen gassing and modifying the percentage of egg yolk, milk, or lecithin are also effective in reducing sperm metabolic activity and the effects of ROS production. Previous studies have reported that the production of ROS may be linked to an aging effect on sperm as ROS production ultimately leads to an apoptotic cascade in which sperm lose their motility, DNA integrity, and vitality (Aitken et al., 2012). Murphy et al. (2015) reported a lower nonreturn rate on d 2 of storage; however, this was only evident in $50 \%$ of the bulls tested, suggesting that individual bulls may be more susceptible to the aging process. The current study supports the notion of a sperm aging effect as a similar reduction in $\mathrm{CR}$ was recorded on $\mathrm{d}$ 2 of storage in 2 bulls used in this study. However, no significant decline occurred in CR in the other 6 bulls from d 1 to 2 of storage.

It is well documented that the physiological status of nulliparous heifers differs from that of lactating cows (Murphy et al., 2015) and that cows with a greater number of DIM more likely to conceive (Hillers et al., 1984), which are both consistent with the findings of this study. As the Irish dairy industry is a seasonal grass-based production system, a high level of fertility is critical to maximize reproductive efficiency within dairy herds, contributing to reducing costs associated with reproductive inefficiencies such as increased calving intervals, involuntary culling (Esslemont et al., 2001), labor costs, as well as increased costs associated with repeated AI (Shalloo et al., 2014).

\section{CONCLUSIONS}

In conclusion, Caprogen, BioXcell, and INRA96 maintained total and progressive sperm motility for a longer period of storage in comparison to OptiXcell, BullXcell, NutriXcell, and AndroMed when diluted semen was stored at a constant temperature. Storing semen at fluctuating temperatures between 4 and $18^{\circ} \mathrm{C}$ had no effect on motility when semen was stored in Caprogen and INRA96, but compromised the motility of liquid bull semen stored in BioXcell, indicating that BioXcell has a reduced ability to protect sperm during temperature fluctuations. The dilution and storage of liquid bull semen in INRA96 resulted in a similar CR to semen diluted in the industry standard, Caprogen. Given that INRA96 can be used directly off the shelf, it may be a suitable alternative to Caprogen for the storage of liquid bull semen. 


\section{ACKNOWLEDGMENTS}

This work was supported by the Irish Research Council, Department of Agriculture, Food and the Marine and Teagasc under grant number EBPPG/2014/60. The authors gratefully acknowledge Munster Cattle Breeding Group, Ballyvorshine, Mallow, Co. Cork, Ireland, for the distribution of straws.

\section{REFERENCES}

Aires, V. A., K.-D. Hinsch, F. Mueller-Schloesser, K. Bogner, S. Mueller-Schloesser, and E. Hinsch. 2003. In vitro and in vivo comparison of egg yolk-based and soybean lecithin-based extenders for cryopreservation of bovine semen. Theriogenology 60:269-279.

Aitken, R. J., K. T. Jones, and S. A. Robertson. 2012. Reactive oxygen species and sperm function - in sickness and in health. J. Androl. 33:1096-1106.

Akhter, S., M. Ansari, B. Rakha, S. Andrabi, S. Iqbal, and N. Ullah. 2010. Cryopreservation of buffalo (Bubalus bubalis) semen in Bioxcell ${ }^{\circledR}$ extender. Theriogenology 74:951-955.

Akhter, S., M. Ansari, B. Rakha, N. Ullah, S. Andrabi, and M. Khalid. 2011. In vitro evaluation of liquid-stored buffalo semen at $5{ }^{\circ} \mathrm{C}$ diluted in soya lecithin based extender (Bioxcell $\left.{ }^{\circledR}\right)$, Tris-citric egg yolk, skim milk and egg yolk-citrate extenders. Reprod. Domest. Anim. 46:45-49.

Al Naib, A., J. Hanrahan, P. Lonergan, and S. Fair. 2011. In vitro assessment of sperm from bulls of high and low field fertility. Theriogenology 76:161-167.

Batellier, F., M. Magistrini, J. Fauquant, and E. Palmer. 1997. Effect of milk fractions on survival of equine spermatozoa. Theriogenology 48:391-410.

Bergeron, A., Y. Brindle, P. Blondin, and P. Manjunath. 2007. Milk caseins decrease the binding of the major bovine seminal plasma proteins to sperm and prevent lipid loss from the sperm membrane during sperm storage. Biol. Reprod. 77:120-126.

Bergeron, A., and P. Manjunath. 2006. New insights towards understanding the mechanisms of sperm protection by egg yolk and milk. Mol. Reprod. Dev. 73:1338-1344.

Black, N. 2006. Artificial insemination of cattle. Anim. Reprod. Sci. Online 10/06/15.

Brito, L. F., A. Silva, L. Rodrigues, F. Vieira, L. Deragon, and J. Kastelic. 2002. Effect of age and genetic group on characteristics of the scrotum, testes and testicular vascular cones, and on sperm production and semen quality in AI bulls in Brazil. Theriogenology 58:1175-1186.

Chaudhari, D., A. Dhami, K. Hadiya, and J. Patel. 2015. Relative efficacy of egg yolk and soya milk-based extenders for cryopreservation $\left(-196^{\circ} \mathrm{C}\right)$ of buffalo semen. Veterinary World 8:239-244.

Crespilho, A., M. Nichi, P. Guasti, C. Freitas-Dell'Aqua, M. Sá Filho, R. Maziero, J. Dell'Aqua, and F. O. Papa. 2014. Sperm fertility and viability following $48 \mathrm{~h}$ of refrigeration: Evaluation of different extenders for the preservation of bull semen in liquid state. Anim. Reprod. Sci. 146:126-133.

Crowe, J. H., J. F. Carpenter, L. M. Crowe, and T. J. Anchordoguy. 1990. Are freezing and dehydration similar stress vectors? A comparison of modes of interaction of stabilizing solutes with biomolecules. Cryobiology 27:219-231.

Crowe, M. A., V. Padmanabhan, M. Mihm, I. Beitins, and J. Roche. 1998. Resumption of follicular waves in beef cows is not associated with periparturient changes in follicle-stimulating hormone heterogeneity despite major changes in steroid and luteinizing hormone concentrations. Biol. Reprod. 58:1445-1450.

De Amicis, I., U. Tosi, A. Carluccio, M. Paoletti, D. Robbe, A. Contri, and F. Russo. 2004. Technical Note: Artificial insemination in rabbits: Laboratory and field trial with three different semen extenders. World Rabbit Sci. 12:65-79. de Paz, P., M. Esteso, M. Alvarez, M. Mata, C. Chamorro, and L. Anel. 2010. Development of extender based on soybean lecithin for its application in liquid ram semen. Theriogenology 74:663-671.

Drobnis, E. Z., L. M. Crowe, T. Berger, T. J. Anchordoguy, J. W. Overstreet, and J. H. Crowe. 1993. Cold shock damage is due to lipid phase transitions in cell membranes: A demonstration using sperm as a model. J. Exp. Zool. 265:432-437.

Esslemont, R., M. Kossaibati, and J. Allcock. 2001. Economics of fertility in dairy cows. BSAS Occasional Publication. 19-30.

Fayrer-Hosken, R., C. Abreu-Barbosa, G. Heusner, and L. Jones. 2008. Cryopreservation of stallion spermatozoa with INRA96 and glycerol. J. Equine Vet. Sci. 28:672-676.

Ferdinand, N., T. D. Ngwa, K. Augustave, B. P. H. Dieudonné, B. O. Willington, T. C. D'Alex, K. Pierre, and T. Joseph. 2014. Effect of egg yolk concentration in semen extender, $\mathrm{pH}$ adjustment of extender and semen cooling methods on bovine semen characteristics. Glob. Vet. 12:292-298.

Foote, R. 2002. The history of artificial insemination: Selected notes and notables. J. Anim. Sci. 80:1-10.

Fukui, Y., H. Kohno, T. Togari, M. Hiwasa, and K. Okabe. 2008. Fertility after artificial insemination using a soybean-based semen extender in sheep. J. Reprod. Dev. 54:286-289.

Gacitua, H., and A. Arav. 2005. Successful pregnancies with directional freezing of large volume buck semen. Theriogenology 63:931-938.

Gil, J., M. Rodriguez-Irazoqui, N. Lundeheim, and L. Söderquist. 2003. Fertility of ram semen frozen in Bioexcell ${ }^{\circledR}$ and used for cervical artificial insemination. Theriogenology 59:1157-1170.

Herold, F., J. Aurich, and D. Gerber. 2004. Epididymal sperm from the African buffalo (Syncerus caffer) can be frozen successfully with AndroMed ${ }^{\circledR}$ and with Triladyl ${ }^{\mathrm{TM}}$ but the addition of bovine seminal plasma is detrimental. Theriogenology 61:715-724.

Hillers, J., P. Senger, R. Darlington, and W. Fleming. 1984. Effects of production, season, age of cow, days dry, and days in milk on conception to first service in large commercial dairy herds. J. Dairy Sci. $67: 861-867$.

Holt, W. 2000. Basic aspects of frozen storage of semen. Anim. Reprod. Sci. $62: 3-22$.

Jiménez-Rabadán, P., M. Ramón, O. García-Álvarez, A. Maroto-Morales, E. Del Olmo, M. Pérez-Guzmán, A. Bisbal, M. FernándezSantos, J. Garde, and A. Soler. 2012. Effect of semen collection method (artificial vagina vs. electroejaculation), extender and centrifugation on post-thaw sperm quality of Blanca-Celtibérica buck ejaculates. Anim. Reprod. Sci. 132:88-95.

Kaeoket, K., T. Srisowanna, U. Wichaidit, P. Chanapiwat, and S. Manee-in. 2010. Comparative study on six different long term commercial extenders for fresh boar semen. Thai J. Vet. Med. $40: 257-263$.

Kasimanickam, R., V. Kasimanickam, A. Tibary, and K. Pelzer. 2011. Effect of semen extenders on sperm parameters of ram semen during liquid storage at $4^{\circ} \mathrm{C}$. Small Rumin. Res. 99:208-213.

Kulaksiz, R., Ç. Çebi, and E. Akçay. 2012. The effect of different extenders on the motility and morphology of ram sperm frozen or stored at $4^{\circ}$ C. Turk. J. Vet. Anim. Sci. 36:177-182.

López-Fernández, C., S. Johnston, A. Gosálbez, and J. Gosálvez. 2011. Seasonal changes in sperm DNA fragmentation of MurcianoGranadina goats: The compelling case for dynamic assessment. Small Rumin. Res. 100:50-53.

Manjunath, P. 2012. New insights into the understanding of the mechanism of sperm protection by extender components. Anim. Reprod. Sci. 9:809-815.

Maxwell, W. M., I. Parrilla, I. Caballero, E. Garcia, J. Roca, E. Martinez, J. Vazquez, and D. Rath. 2007. Retained functional integrity of bull spermatozoa after double freezing and thawing using PureSperm ${ }^{\circledR}$ density gradient centrifugation. Reprod. Domest. Anim. 42:489-494.

Murphy, C., A. Fahey, A. Shafat, and S. Fair. 2013. Reducing sperm concentration is critical to limiting the oxidative stress challenge in liquid bull semen. J. Dairy Sci. 96:4447-4454.

Murphy, C., S. A. Holden, E. M. Murphy, A. R. Cromie, P. Lonergan, and S. Fair. 2015. The impact of storage temperature and sperm 
number on the fertility of liquid-stored bull semen. Reprod. Fert. Develop. Online (Bergh.) https://doi.org/10.1071/RD14369.

O'Hara, L., J. Hanrahan, L. Richardson, A. Donovan, S. Fair, A. Evans, and P. Lonergan. 2010. Effect of storage duration, storage temperature, and diluent on the viability and fertility of fresh ram sperm. Theriogenology 73:541-549.

Oliveira, L. Z., E. C. C. Celeghini, F. M. Monteiro, and R. P. de Arruda. 2013. The importance of semen quality in AI programs and advances in laboratory analyses for semen characteristics assessment. INTECH Open Access Publisher. 1-16.

Olivera-Muzante, J., S. Fierro, and J. Gil. 2011. Conception rates in ewes after AI with ram semen preserved in milk-egg yolk extenders supplemented with glycerol. Reprod. Domest. Anim. 46:508-512.

Pillet, E., F. Batellier, G. Duchamp, V. Furstoss, Y. L. Vern, D. Kerboeuf, M. Vidament, and M. Magistrini. 2008. Freezing stallion semen in INRA96 ${ }^{\circledR}$-based extender improves fertility rates in comparison with INRA82. Dairy Sci. Technol. 88:257-265.

Rehmana, F. U., C. Zhaoa, M. A. Shaha, M. S. Qureshib, and X Wanga. 2013. Semen extenders and artificial insemination in ruminants. Veterinaria 1:1-8.

Saha, R., A. Ashraf, and Z. Rahman. 2014. Comparative study on conception rate of cow in using frozen and liquid semen. J. Anim. Sci. Adv. 4:749-772.

Sahashi, Y., T. Otsuki, S. Higaki, M. Nagano, Y. Yamashita, and M. Hishinuma. 2011. Effect of butylated hydroxytoluene on dog sperm longevity in chilling storage and cryopreservation. J. Vet. Med. Sci. 73:895-899.

Shalloo, L., A. Cromie, and N. McHugh. 2014. Effect of fertility on the economics of pasture-based dairy systems. Animal 8:222-231.

Shannon, P. 1965. Contribution of seminal plasma, sperm numbers, and gas phase to dilution effects of bovine spermatozoa. J. Dairy Sci. 48:1357-1361.
Shannon, P. 1968. Advances in semen dilution. Proc. N.Z. Soc. Anim. Prod. 28:23-31.

Shannon, P., B. Curson, and A. Rhodes. 1984. Relationship between total spermatozoa per insemination and fertility of bovine semen stored in Caprogen at ambient temperature. N. Z. J. Agric. Res. $27: 35-41$.

Sharafi, M., M. Forouzanfar, S. M. Hosseini, M. Hajian, S. Ostadhosseini, L. Hosseini, P. Abedi, N. Nili, H. R. Rahmani, and A. R Javaheri. 2009. In vitro comparison of soybean lecithin based-extender with commercially available extender for ram semen cryopreservation. Int. J. Fertil. Steril. 3:149-152.

Stradaioli, G., T. Noro, L. Sylla, and M. Monaci. 2007. Decrease in glutathione (GSH) content in bovine sperm after cryopreservation: Comparison between two extenders. Theriogenology 67:1249-1255.

van den Berg, B., J. Reesink, and W. Reesink. 2014. TRIXcell+, a new long-term boar semen extender containing whey protein with higher preservation capacity and litter size. Open Vet J. 4:20-25.

van Wagtendonk-de Leeuw, A. M., R. Haring, L. Kaal-Lansbergen, and J. Den Daas. 2000. Fertility results using bovine semen cryopreserved with extenders based on egg yolk and soy bean extract. Theriogenology 54:57-67.

Verberckmoes, S., A. Van Soom, J. Dewulf, I. De Pauw, and A. De Kruif. 2004. Storage of fresh bovine semen in a diluent based on the ionic composition of cauda epididymal plasma. Reprod. Domest. Anim. 39:410-416.

Vishwanath, R., C. Pitt, and P. Shannon. 1996. Sperm numbers, semen age and fertility in fresh and frozen bovine semen. Translated by New Zealand Society for Animal Production. 31-34.

Vishwanath, R., and P. Shannon. 2000. Storage of bovine semen in liquid and frozen state. Anim. Reprod. Sci. 62:23-53. 